\title{
Understanding Perceived Values and Behavioral Effects of Mobile Apps: An Abstract
}

\author{
Ines Hackeradt
}

\begin{abstract}
Mobile apps enable brands and retailers to enrich today's customer's shopping path with different services. But the number of app downloads, which was growing in the past years, has recently begun to slow down somewhat, making it more difficult for a marketer to provide a successful app to customers. To fulfill market needs, we therefore need a better understanding of how consumers perceive values evoked by these apps and their effects on customer behavior. The aim of this paper is to analyze perceived values in mobile apps and how they are able to enrich (non-digital) customer shopping experience. A first pilot study was set up in a shopping mall, and further experiments are conceptualized. Findings suggest that consumers see social value as important part of shopping experience and mobile shopping apps can support this social need. Moreover, it is found that economic and hedonic value enhances the intention to use a mobile shopping app and improve shopping experience. Thus, contribution is given for consumer value theory as well as from a managerial point of view to improve mobile app strategies. One implication is that hedonic and social values have a high impact on customer shopping experience and therefore it is surprising that those values are underestimated in mobile marketing research so far.
\end{abstract}

References Available Upon Request

I. Hackeradt $(\bowtie)$

University of Goettingen, Goettingen, Germany

e-mail: ihacker@uni-goettingen.de 